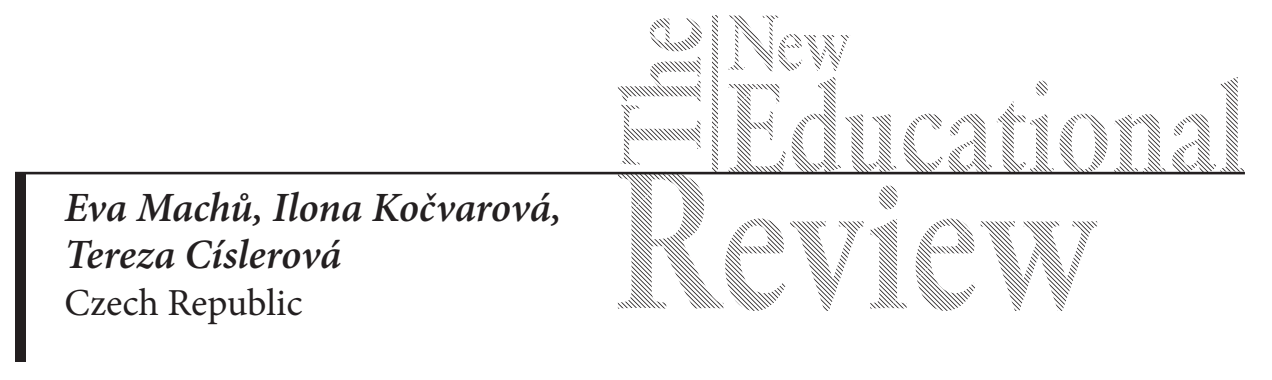

\title{
Labeling in the Education of Gifted Pupils
}

\begin{abstract}
The study presents an analysis of teachers' tendency to label gifted pupils. A questionnaire was used at the level of lower secondary education. It was aimed at teachers' educational strategies in the area of enriching the curriculum for gifted pupils, and teachers' tendency to label gifted pupils. In conclusion, labeling does not belong to educational strategies of most teachers. Gender, pedagogical qualifications and the length of teaching experience do not influence teachers' tendency to label gifted pupils. Teachers from specialized schools for gifted pupils have a stronger tendency to label them. This tendency is weaker in the case of teachers from small schools.
\end{abstract}

Keywords: giftedness, gifted pupil, labeling, enrichment curicullum

\section{Introduction and theoretical definitions}

Giftedness is most frequently defined as an individual's skill in a selected area which is appraised by the social-cultural environment and is quantitatively and qualitatively more developed in comparison with their peers (Heward, 2013). Porter (1999) claims that these definitions may gain a more specific form in relation to their conception. It is, for instance, the liberal versus the conservative conception (they differ in the estimation of the amount of the gifted in the population), monoversus multidimensional (according to the number of criteria for identifying giftedness), definition of potential versus manifested performance. Our conception of giftedness is based on multidimensional liberal definitions and is focused on the intellectual giftedness. A gifted pupil is defined not only as a pupil diagnosed by a pedagogical-psychological center, but also a pupil who has not been diagnosed so far, but manifests features of intellectual giftedness. 
Labeling is a sociological theory dealing with the process of individuals being labeled in order to describe their abilities and skills. After labeling, the approach of professionals who get in contact with the individuals differs. The approach of the social environment differs as well, the self-concept changes, which leads to stigmatization (Hudak, Kihn, 2001). Should we look into the development of labeling theory, with the exception of early theories (e.g. F. Tannenbaum, G.H. Mead, E. Lemert), the issue took center stage during the 1960s. The theory was popularized mainly by the book Outsiders by H.W. Becker and Stigma by E. Goffman (Munková, 2004).

Labeling gains its context mainly in connection with the sociological theory of the development of deviant behavior (Urban, 2011). Other attributes, such as the level of an individual's giftedness, may also be seen as stigmatizing. The attribute "gifted" develops during the identification of giftedness and the individual is labeled by the subjects developing the individual's giftedness or only getting in contact with the individual. The label then also influences the creation of the person's social identity (Gates, 2010). Labeling connected with giftedness is mentioned by many leading authors, e.g. Matthews and Foster (2005), Renzulli (2004), Freeman (1998), Heward (2013) and Clark (2013). Research into giftedness is conducted not only in school environment, but also in family and peer environments, and is based mainly on quantitative research methods. If we focus on the research into school environment (e.g. Gates, 2010; Renzulli, 2004; Moulton et al, 1998), the results show the negative, but also the positive consequences of labeling. Among the negative consequences, which are mainly so-called social aspects, we can find, e.g., stereotypical evaluation of the gifted pupil's personality, the gifted pupil's fear of academic failure, peer pressure, and heightened expectations of teachers and parents, which does not match the pupil's level of giftedness. Among the positive aspects, which are mainly so-called personal and academic aspects, we can mention, e.g., influencing the teacher's expectations offer of enriching educational methods and tools for the labeled pupil, heightened individual educational approach to the pupil, interactions with other gifted pupils, etc.

Heward (2013) claims that the labeling of individuals is a common part of child care, which follows the output of educational diagnostics. On the contrary, Clark (2013) is aware of the negative consequences of labeling. In his book, Clark gives some general advice for educators on how to treat labeling and explain the meaning of this term to children. Moreover, if we follow the principles of inclusive education, which are nowadays becoming relevant, it is important to eliminate educational strategies leading to inappropriate and unnecessary labeling of gifted pupils in the classroom. 
Our research thematically followed our own qualitative research probe, which used quotations of gifted children, their classmates and teachers, to describe the process of labeling using grounded theory (Machů, 2013). Inadequate educational strategies, which are the cause or support of labeling, included: application of an enriching curriculum only to pupils diagnosed as gifted, above standard material equipment of classrooms with gifted pupils, media promoting of kids labelled as gifted, etc. The aforementioned strategies resulted in excluding gifted pupils from the collective of classmates, mocking gifted pupils by their classmates, rivalry, jealousy over above-standard material equipment of classrooms.

For our follow-up quantitative research, we selected only the aforementioned educational strategies, which a teacher of the second level of primary school may use, and which are related to the application of instructions differentiated by the teacher and are employed when applying the so-called enriching curriculum. These strategies included differentiation of the contents, processes, products and educational environment (Tomlinson, 2013). Questionnaire items were based on the chosen parts of the enriching curriculum. Labeling strategies may be used in all these modifications and are not essential for the successful development of the pupil's giftedness, i.e. applying these labeling strategies is completely unpurposeful and unnecessary. The items of the questionnaire were designed to find out whether teachers take care of gifted pupils, and if so, if the differentiated instructions foster labeling or not. We also assumed that applying the differentiated instructions, which does not lead to the tendency of labeling of gifted pupils, was related to the teacher's expertise and to the orientation of the school, and therefore, we selected research assumptions connected with the length of the pedagogical experience, pedagogues' certification and whether they work at common primary school, selective school, or school with a lower or higher number of pupils.

\section{Research Methodology}

The main goal of the research was to analyze teachers' tendency to label gifted pupils in connection with the chosen socio-demographic characteristics of teachers. A partial goal was to find out whether teachers had a tendency to idleness in the care of gifted pupils (tendency to idleness), took care of gifted pupils with a tendency to label them (tendency to labeling), or took care of gifted pupils and avoided labeling (ideal approach to the gifted). The research design results from our own broader analysis carried out within the framework of the research aimed 
at evaluation of schools' and teachers' quality of care of gifted pupils in the Czech Republic (Machů, Kočvarová, 2013).

We stated the following hypotheses:

H1: Teachers' tendency to label gifted pupils is lower than their tendency to idleness in the care of gifted pupils.

H2: The tendency to label gifted pupils is not different in terms of teachers' gender.

H3: Certified teachers show a lower tendency to label gifted pupils than uncertified ones.

H4: The tendency to label gifted pupils decreases with an increase in the length of teaching practice.

H5: Teachers working at specialized schools for gifted pupils or secondary grammar schools with the length of study of eight years exhibit a higher tendency to label gifted pupils than teachers working at common primary schools.

H6: Small schools exhibit a lower tendency to labeling gifted pupils than other types of schools.

Research sample was formed by 609 respondents, teachers from the Czech Republic. They optionally entered the research on the basis of a preceding electronic invitation sent to lower secondary education teachers. The sample can be characterised as follows: There were 451 women (74\%) and 158 men (26\%) of the average age of 46, with the length of teaching practice of approximately 21 years. It was composed of 560 certified teachers (92\%) and 49 uncertified teachers (8\%). Detailed characteristics of the research sample are presented in connection with the conducted steps of the analysis.

The research tool used was an originally constructed questionnaire, which was validated with the use of exploratory factor analysis and demonstrated acceptable reliability ( $\alpha=0.77$ ) (for more details cf., Machů, Kočvarová, pp. 62-67). Except for the demographic data, it contains 19 items, which are aimed at school quality. Items referring to problematic issues of labeling gifted pupils were extracted from the questionnaire.

The model of the answers can be characterised as follows:

- Gifted pupils' abilities are not being developed, therefore there is no labeling of gifted pupils (in the framework of the analysis denoted as "tendency to idleness", hereinafter indicated as $O$ );

- Gifted pupils' abilities are being developed, but in the way in which there is no labeling ("tendency to labeling", indicated as $L$ ); 
- Gifted pupils' abilities are developed and at the same time labeling is eliminated. ("ideal approach to gifted pupils", indicated as I).

Chart 1. Items chosen from the questionnaire and their denotation

$\mathbf{P} \quad$ a) School has got few didactic facilities for pupils' gift and talent development. $O$

11 b) School has got enough didactic facilities for pupils' gift and talent development. These facilities can be used equally by all the pupils of the class or year of study. I

c) School has got enough didactic utilities for pupils' gifts and talent development. These utilities are used by gifted pupils only, whom they are dedicated to. $L$

$\mathbf{P} \quad$ a) Teachers differentiate between the basic and enriching curriculum. Both types of curricu-

21 lum are dedicated to all the pupils. $O$

b) Teachers differentiate between the basic and enriching curriculum, whereas the enriching curriculum is dedicated to gifted pupils only. $L$

c) Teachers differentiate between the basic and enriching curriculum, whereas the enriching curriculum is dedicated to all the pupils who have mastered the basic curriculum. I

$\mathrm{P} \quad$ a) During revision of the curriculum all the pupils work on the same tasks. $O$

22 b) Gifted pupils revise for much shorter time. They dedicate their time to other elaborate activities. $L$

c) During revision of the curriculum all the pupils work on the same tasks. If the teacher finds out that some students have mastered the curriculum, they can dedicate their time to other elaborate activities. I

$\mathrm{P} \quad$ a) Teachers impose the same requirements for the results of education on all the students

23 of the class. All the pupils have to meet the goals of the basic curriculum. Gifted pupils are intentionally made to meet the goals of the enriching curriculum. $L$

b) Teachers impose the same requirements for the results of education on all the students of the class. All the pupils have to meet the goals of the basic and enriching curriculum. $O$

c) Teachers impose requirements for the results of education on all the students according to their abilities. Pupils who have mastered the basic curriculum work on the enriching curriculum. I

$\mathrm{P} \quad$ a) Teachers' approach to education and its content is uniform. They develop all the pupils in

25 the same way. $O$

b) Teachers' approach to education and its content is different, they intentionally develop the gifts and talents only of the pupils diagnosed as gifted. L

c) Teachers develop pupils' gifts and talents during common lessons without differentiating between pupils diagnosed as gifted, or not. I

\section{Data analysis}

Let us now focus on the findings of the statistical analysis of selected questionnaire items. Data were analyzed using appropriate descriptive and relational statistical methods in the Statistica program, and are described below in the context of specific steps of the analysis performed. 
First, we were interested in what proportion of the respondents chose the offered answers, and whether the most frequently selected ones were statistically significantly superior to other options. We conducted the analysis based on the comparison of the responses in the table of frequency using the goodness of fit of chi-squared test. It turned out that in all the cases the respondents preferred the ideal approach to gifted pupils, which means such practices of care of gifted pupils in which their gifts and talents are developed and at the same time there is no labeling (sign. $<0.001$ ). In all the cases it forms a significant majority of the respondents.

Chart 2. Outcomes of data analysis

\begin{tabular}{lccccccc}
\hline $\begin{array}{l}\text { Types of } \\
\text { answers }\end{array}$ & Tendency to idleness & \multicolumn{2}{l}{ Tendency to labeling } & \multicolumn{2}{l}{$\begin{array}{l}\text { Ideal approach } \\
\text { to gifted pupils }\end{array}$} & \multirow{2}{*}{ sign. } \\
\cline { 1 - 7 } Frequency & $\mathbf{n}$ & $\%$ & $\mathbf{n}$ & $\%$ & $\mathbf{n}$ & $\%$ & \\
\hline P11 & 143 & 23.48 & 59 & 9.69 & 407 & 66.83 & $<0.001$ \\
\hline P21 & 115 & 18.88 & 65 & 10.67 & 429 & 70.44 & $<0.001$ \\
\hline P22 & 85 & 13.96 & 58 & 9.52 & 466 & 76.52 & $<0.001$ \\
\hline P23 & 42 & 6.90 & 159 & 26.11 & 408 & 67.00 & $<0.001$ \\
\hline P25 & 121 & 19.87 & 39 & 6.40 & 449 & 73.73 & $<0.001$ \\
\hline
\end{tabular}

In the context of the prevailing positive results we cannot ignore the statements showing that some teachers do not develop giftedness or develop it inappropriately in terms of labeling theory. Let us focus on the chosen results from Chart 2, showing the tendency to idleness or labeling. More than $26 \%$ of the teachers lead only the gifted pupils to meeting the goals of the enriching curriculum (P23). Their selection does not follow the pupils' actual performance in the given curriculum, but it is based on precedent selection of individuals who (based on their label) get a chance to reach higher goals. Approximately $19 \%$ of the teachers admit, in the questionnaire items P21 and P25, that they develop all the pupils in the same way, and that differentiating between the basic and enriching curriculum is not a tool to differentiate the pupils according to their actual performance. Furthermore, more than $23 \%$ of the teachers admit that they do not have enough didactic resources to develop their students' gifts and talents (P11), but we think that by saying this they just try to make an excuse. At the level of individual items, from 7 to $23 \%$ of the respondents show the tendency to idleness, and 6 to $26 \%$ of the respondents show the tendency to labeling.

If we look at the average tendency of the respondents to label pupils, we will come to the following results, shown in Chart 3. 
Chart 3. Tendency to labeling

\begin{tabular}{lccccccc}
\hline $\begin{array}{l}\text { Tendency to } \\
\text { labeling }\end{array}$ & Mean & Median & Mode & $\begin{array}{c}\text { Mode } \\
\text { frequency }\end{array}$ & Min. & Max. & SD \\
\cline { 2 - 8 } & 0.62 & 0 & 0 & 338 & 0 & 4 & 0.83 \\
\hline
\end{tabular}

The tendency to labeling could reach the value of 0 to 5 points. The average score of the respondents was 0.62 points, but the prevailing value reached in the area of labeling was 0 points (in 338 cases, which makes up more than $55 \%$ of the sample). None of the teachers reached the maximum of 5 points and only $3 \%$ of the teachers reached 3 and more points in the frame of the mentioned tendency. It appears that if we rely on the teachers' answers only, labeling is a marginal phenomenon in the field of care of gifted pupils.

The analysis also showed that in 4 out of 5 extracted items, the teachers prefer idleness towards gifted pupils to practices labelled as inadequate from the point of view of labeling pupils. The tendency to idleness shows a slightly worse average result of 0.83 points. Even in this case, the majority of the respondents, 314 teachers, did not receive any "penalty points".

Chart 4. Tendency to idleness

\begin{tabular}{lccccccc}
\hline $\begin{array}{l}\text { Tendency to } \\
\text { idleness }\end{array}$ & Mean & Median & Mode & $\begin{array}{c}\text { Mode } \\
\text { frequency }\end{array}$ & Min. & Max. & SD \\
\cline { 2 - 8 } & 0.83 & 0 & 0 & 314 & 0 & 5 & 1.07 \\
\hline
\end{tabular}

The comparison of the respondents' tendency to labeling and idleness in terms of care of gifted pupils, using the Wilcoxon Paired Test, shows that the respondents have a significantly higher tendency to idleness than to labeling (sign. $<0.001$ ). Thus, $\mathrm{H} 1$ hypothesis is confirmed.

Then we focused on the characteristics of the teachers who, in their responses, showed the tendency to label pupils. We tested the connection of the teachers' gender and qualifications with the tendency to labeling, using the Mann-Whitney $\mathrm{U}$ - Test. The null hypothesis was confirmed in all the cases. There were no significant differences between the teachers' gender (sign. 0.134) and their qualifications (sign. 0.686). Based on the results, hypothesis $\mathrm{H} 2$ was confirmed, hypothesis $\mathrm{H} 3$ was disproved.

We divided the teachers into 3 groups, regarding the length of their teaching practice. We consideres the teachers with the length of teaching practice less than 5 years as novice teachers ( $7 \%$ of the sample), those with the length of practice from 
6 to 22 years as experienced ones (45\%), and those with the length of practice over 23 years as experts (48\%). We decided to use the Kruskal-Wallis Test and Multiple Comparison of $\mathrm{P}$ values. The result confirmed the null hypothesis (sign. 0.685) and diosproved hypothesis $\mathrm{H} 4$. The teachers' length of practice does not affect their tendency to labeling gifted pupils.

Using the Kruskal-Wallis Test and Multiple Comparison of P values we proved the connection between the teachers' pertinence to a specific type of school and their tendency to labeling. The teachers working at specialized schools for gifted pupils show a statistically higher tendency to labeling in comparison to the common primary school teachers (sign. 0.023). The difference was not proved when comparing the secondary grammar schools with the length of study of 8 years to the common primary schools (sign. 0.580 ). The performed analysis disproved hypothesis $\mathrm{H} 5$.

Chart 5. Tendency to labeling in terms of the type of the school

\begin{tabular}{lccccc}
\hline Type of school & $\begin{array}{c}\text { Number } \\
\text { of respondents }\end{array}$ & Mean & Min. & Max. & SD \\
\hline Primary school & 468 & 0.57 & 0 & 4 & 0.80 \\
\hline Grammar school & 98 & 0.70 & 0 & 4 & 0.80 \\
\hline Special school & 43 & 1.02 & 0 & 4 & 1.08 \\
\hline Total & 609 & 0.62 & 0 & 4 & 0.83 \\
\hline
\end{tabular}

The last part of the analysis was aimed at observing the relationship between the tendency to labeling and size of the school at which the teachers worked. We observed the sizes of the schools in terms of the number of students in 4 groups. We dealt predominantly with the stratification of small, middle-sized and big schools (up to 50, 150, 300 pupils). The schools with the number of students over

Chart 6. Tendency to labeling in terms of size of school

\begin{tabular}{lccccc}
\hline Size of school & $\begin{array}{c}\text { Number } \\
\text { of respondents }\end{array}$ & Mean & Min. & Max. & SD \\
\hline Fewer than 50 & 36 & 0.25 & 0 & 3 & 0.60 \\
\hline Fewer than 150 & 97 & 0.59 & 0 & 4 & 0.84 \\
\hline Fewer than 300 & 178 & 0.59 & 0 & 4 & 0.80 \\
\hline More than 300 & 298 & 0.70 & 0 & 4 & 0.85 \\
\hline Total & 609 & 0.62 & 0 & 4 & 0.83 \\
\hline
\end{tabular}


300 were not divided into any other groups. Analysis, using the Kruskal-Wallis Test and Multiple Comparison of $\mathrm{P}$ values, proved that the teachers working at smaller schools demonstrate a smaller tendency to labeling than those working at the schools having more than 300 pupils (sign. 0.012). Differences among other compared groups were not statistically important (sign. > 0.05). Hypothesis H6 was rejected.

\section{Summary, discussion and conclusion}

Based on the research results, we can conclude that labeling does not belong to the educational strategies of the vast majority of Czech teachers working in lower secondary schools. Based on self-evaluation, 6 to $26 \%$ of the teachers admitted the tendency to labeling pupils at the level of individual items in the questionnaire. Only $3 \%$ of the teachers chose the strategy of labeling in most of the studied questionnaire items. The teachers having problems with treating gifted pupils tend not to care for them rather than applying the procedures leading to their labeling. It is debatable which option is better from the pedagogical point of view. Based on the above theoretical analysis, we think that from the short-term point of view, strategies leading to labeling pupils are better than idleness because they are a proof that teachers want to devote their time to individual care of gifted pupils and try to treat them correctly.

We also analysed the relationship of selected factors with the tendency to labeling. We found out that teachers' gender does not affect their tendency to labeling gifted pupils, nor do their qualifications and length of teaching practice. The teachers working at specialized primary school for gifted pupils have a higher tendency to labeling in comparison with the teachers working at common primary schools. We also found out that the teachers working at small schools (up to 50 pupils) have a lower tendency to labeling in comparison with the teachers from big schools (over 300 pupils).

As already stated, the survey was conducted as a part of broader research on the quality of care that schools offer to gifted pupils. (Machů, Kočvarová, 2013). The results can therefore be interpreted in its context. Broader research showed that the quality of care of gifted pupils is related to the size of the school. Teachers working at small schools (fewer than 50 pupils) show a higher quality of care in comparison with other types of schools. We can now add that teachers working at small schools have the lowest tendency to labeling. 
Therefore, it is evident that high-quality care of gifted pupils is not related to the specialization of schools as much as to their size. Small schools usually have fewer students in the classroom. We assume that they offer a better atmosphere for establishing stronger social ties between teachers and their students and for an individual approach and differentiation.

After presenting our findings, it should be noted that there were certain limitations associated with the research. We consider simplification of the educational reality for 3 possible answers and subjecting them to artificial data metrization as the greatest limitation. We are aware that the outcomes of our research are relative, simplified and contributory to the paradigm through which we carried out the evaluation of the teachers' answers. Another limitation is connected with the research sample selection. The teachers who voluntarily joined the research showed a positive approach to the observed issues. The sample of respondents is therefore not considered to be comparable with general teaching population, but rather as a positive deviation from the average (the fact that almost a half of the respondents were teachers with the teaching experience of more than 23 years was also taken into consideration). Therefore, the results may seem better than the actual situation in the care of gifted pupils. We realize that teachers could describe the application of their educational strategies in a better way than they really are. On the other hand, we can treat the research results not only from the perspective of what educational strategies teachers use, but also which educational strategies they believe to be suitable for the development of giftedness. Another problem was that the selected items of the questionnaire explored a very narrow part of forms of the labeling of gifted students. For this reason, we plan to carry out extensive follow-up research combined with direct observation of the teaching process.

\section{Acknowledgments}

The article was realized as a part of IGA project no. SV60131307020/2110.

\section{References}

Clark, B. (2013). Growing up gifted. Developing the potential of children at home and at school. California: Pearson.

Freeman, J. (1998). Educating the Very Able. Current International research. London: Stationery Office.

Gates, J. (2010). Children With Gifts and Talents: Looking Beyond Traditional Labels. Roeper Review, 32 (3), 200-206. 
Heward, W.L. (2013). Exceptional Children. An Introduction to Special Education. Ohio: Pearson Education.

Hudak, G. Kihn, P. (2001). Labeling: Pedagogy and Politics. USA: Routledge.

Machů, E. (2013). Causes and Consequences of Labelling Gifted Pupils at Selected Elementary Schools. The New Educational Review, 31 (1), 185-194.

Machů, E., Kočvarová, I. (2013). Kvalita školy z hlediska péče o nadané žáky. Zlín: Univerzita Tomáše Bati ve Zlíně.

Moulton, P. et al. (1998). Gifted \& Talented: Exploring the Positive and Negative Aspects of Labeling. Roeper Review, 21 (2), 105-120.

Munková, G. (2004). Sociální deviace. Praha: Karolinum.

Porter, L. (1999). Gifted Young Children. A guide for teachers and parents. Buckingham: Open University Press.

Renzulli, J.S. (Ed.) (2004). Identification of Students for Gifted and Talented Programs. California: Corvin Press.

Tomlinson, A. (2013). Differentiated instruction. In Callahan,C.M, Herberg-Davis, H.L. Fundamentals of Gifted Education. Considering Multiple Perspectives. NY and London: Routledge.

Urban, L. (2011). Sociologie trochu jinak. Praha: Grada. 